\title{
BMJ Open Association between hepatitis C virus infection and osteoporotic fracture risk among postmenopausal women: a cross- sectional investigation in Taiwan
}

\author{
Ming-Shyan Lin, ${ }^{1,2}$ Po-Han Chen, ${ }^{3}$ Po-Chang Wang, ${ }^{1,2}$ Huang-Shen Lin, ${ }^{4}$ \\ Tung-Jung Huang, ${ }^{5,6}$ Shih-Tai Chang, ${ }^{1,2}$ Wen-Nan Chiu, ${ }^{7}$ Mei-Yen Chen ${ }^{1,8,9}$
}

To cite: Lin M-S, Chen P-H, Wang P-C, et al. Association between hepatitis $C$ virus infection and osteoporotic fracture risk among postmenopausal women: a cross-sectional investigation in Taiwan. BMJ Open 2019;9:e021990. doi:10.1136/ bmjopen-2018-021990

- Prepublication history for this paper is available online. To view these files, please visit the journal online (http://dx.doi.org/)

Received 30 January 2018 Revised 24 August 2018 Accepted 5 November 2018

Check for updates

(C) Author(s) (or their employer(s)) 2019. Re-use permitted under CC BY-NC. No commercial re-use. See rights and permissions. Published by BMJ.

For numbered affiliations see end of article.

Correspondence to Professor Mei-Yen Chen; meiyen@gw.cgust.edu.tw

\section{ABSTRACT}

Purpose Early low bone mass is a risk factor for osteoporotic fractures associated with multiple factors, including menopause and chronic liver diseases. Hepatitis $\mathrm{C}$ virus (HCV) also plays a major role in chronic liver disease and has many extrahepatic consequences, such as decreased bone mineral density (BMD). This study aimed to examine the hypothesis that HCV seropositivity is independently associated with menopausal BMD loss. Methods This community-based, cross-sectional study was based in two rural townships in Yunlin County, Taiwan. A total of 636 menopausal women aged $45-80$ years who underwent annual health checks were included. Viral markers of HCV, dual-energy X-ray absorptiometry and fracture risk assessment tool (FRAX) scores were measured. Logistic regression analysis was performed to assess the association between various predictors and the presence of low BMD.

Results The participants (median age: 65 years) had a HCV seropositivity rate of $32.2 \%$. BMD was significantly lower in the HCV-seropositive participants in different anatomic locations than in the seronegative individuals (lumbar spine: -1.5 vs -1.1 ; total hip: -0.9 vs -0.6 ; femoral neck: -1.2 vs $-1.0 ; p<0.05)$. HCV-seropositive subjects had higher rates of major osteoporotic fractures $(11.3 \% \pm 7.6 \%$ vs $9.0 \pm 6.8 \% ; p<0.001)$ and hip fractures $(3.4 \% \pm 4.7 \%$ vs $2.3 \pm 4.9 \% ; p=0.006)$ and a higher risk of lower BMD (osteopenia and osteoporosis) based on a multivariable regression analysis (adjusted OR: $1.8 ; 95 \% \mathrm{Cl}$ 1.16 to $2.81 ; p=0.009$ ).

Conclusions HCV infection may be an independent risk factor for menopausal BMD loss and fractures predicted by FRAX.

\section{INTRODUCTION}

Osteoporosis leads to increased bone fragility, fracture and disability and is an important health issue in menopausal women, who have a higher prevalence $(13 \%-23.3 \%)$ of osteoporosis $^{1}$ and a fourfold higher mortality due to osteoporosis than men. ${ }^{2}$ Apart from traditional risk factors, ${ }^{3}$ chronic liver disease potentially contributes to osteopenia and osteoporosis. ${ }^{4}$ These may be associated with

\section{Strengths and limitations of this study}

- Few studies have reported the association between hepatitis $\mathrm{C}$ virus (HCV) infection and bone mineral density (BMD) loss among postmenopausal women.

- These results highlight the prevalence of the HCV infection in southern Taiwan and the strong association between HCV seropositivity and lower BMD in postmenopausal women.

- The relationship of HCV seropositivity and the fracture risk assessment tool score, which is more feasible for the evaluation of a 10-year potential fracture rate.

- The limitations of the study include its non-randomised sampling strategy, the duration of the HCV infection, viral load, nutrition status and recruitment of individuals with community elders, which may hinder the generalisation of our findings.

alcohol consumption, ${ }^{5}$ steroid use ${ }^{6}{ }^{\text {vitamin }}$ D deficiency, ${ }^{7}$ chronic cholestatic disease ${ }^{8}$ or advanced liver cirrhosis. ${ }^{9}$ Because viral cirrhosis is associated with a high osteoporosis incidence $(20 \%-53 \%)$ and potential fractures, ${ }^{10}$ the guideline-directed therapy for viral hepatitis has been aggressively adopted for menopausal women. ${ }^{11}$

In the global hepatitis report, the WHO estimated that in 2015, roughly 71 million of people were living with hepatitis $\mathrm{C}$ virus (HCV) infection worldwide, representing $1.0 \%$ of the population, ${ }^{12}$ with a high HCV prevalence of $6 \%-30 \%$ in southern Taiwan. ${ }^{13}$ Chronic hepatitis B or Cinfection both reduce bone mineral density (BMD) in non-cirrhotic population. ${ }^{14}$ In addition to extrahepatic complications, ${ }^{15}$ chronic HCV infection increases the incidence of osteoporosis ${ }^{16}$ and fractures ${ }^{17}$ associated with overt cirrhosis ${ }^{18}$ or coinfection with HIV. ${ }^{19}$ Beyond routine BMD evaluation as a T-score, ${ }^{20}$ the fracture risk assessment tool (FRAX) is another simple and well-validated prediction for future 
fractures based on clinical and personal risk characteristics. ${ }^{21}$ Although Nicoll $e t a l^{22}$ had used the FRAX score to study a cirrhotic population, an associated analysis of menopausal women with HCV is lacking. Therefore, we hypothesised that HCV-seropositive menopausal women had lower T-scores and higher FRAX-predicted fracture rates than $\mathrm{HCV}$-seronegative women.

\section{METHODS}

\section{Design, sample and setting}

Between October 2015 and July 2016, 1070 women living in a coastal Yunlin County (Taiwan) village underwent a community-based annual health check, including a dual-energy X-ray absorptiometry (DXA) BMD analysis. We enrolled 636 menopausal women, after excluding those aged $>80$ or $<40$ years. We also excluded women who underwent premature menopause (aged $<40$ years); had missing laboratory, viral markers or anthropometric data; or who had histories of hormone replacement therapy, osteoporotic medications, liver cirrhosis, hepatic surgery or hepatic lesions. All participants completed baseline questionnaires and provided informed consent before undergoing examinations.

\section{Laboratory assessments}

After an overnight 12 hours fast, venous blood samples were obtained from all study participants. The serum samples were analysed (7600 Chemistry Analyzer; Hitachi Medical, Tokyo, Japan) to determine fasting plasma glucose, serum creatinine, alanine aminotransferase, aspartate aminotransferase, uric acid, triglyceride, total cholesterol, high-density lipoprotein cholesterol and low-density lipoprotein cholesterol levels. Viral markers of $\mathrm{HCV}$ and hepatitis B virus (HBV) infections were assessed by using specific RNA antibodies in an electrochemiluminescence immunoassay or semiquantitative determination of hepatitis B surface antigens by using a sandwich radioimmunoassay (Elecsys E-170; Cobas Analyzer; Roche Diagnostics, Indianapolis, Indiana, USA), respectively.

\section{Blood pressure (BP) and anthropometric measurements}

A non-invasive oscillometric monitor (Omega 1400; InVivo Research, Orlando, Florida, USA) was calibrated and used to measure BP, following a standardised procedure. Each participant's BP was measured twice and recorded. If the difference between the first and second $\mathrm{BP}$ values was $>10 \mathrm{~mm} \mathrm{Hg}$, the BP was measured a third time. The mean $\mathrm{BP}$ value was calculated using the two closest $\mathrm{BP}$ values and the value used in the subsequent analyses. Height $(\mathrm{cm})$ and body weight $(\mathrm{kg})$ were recorded, with the individuals wearing light clothing and no shoes. Each participant's body mass index (BMI) was calculated using the standard formula $\left(\mathrm{kg} / \mathrm{m}^{2}\right)$ and grouped according to the Lipschitz classification. ${ }^{23}$ An anthropometric tape was used to measure waist and hip circumferences. Waist circumference was measured at a level midway between the lowest rib margin and the iliac crest, whereas hip circumference was measured, in the standing position, at the level of the maximum buttocks protuberance.

\section{Lifestyle and medical history}

We checked the participants' habits regarding alcohol consumption, betel nut chewing and cigarette smoking by using baseline questionnaires. Current user (participants were currently drinking/chewing/smoking) and non-user (participants who had never drank/chewed/ smoked, or had not done so, during the previous year) designations were defined and used to classify the participants.

\section{BMD by DXA examination}

$\operatorname{BMD}\left(\mathrm{g} / \mathrm{cm}^{2}\right)$ and T-scores were assessed from each participant in the lumbar spine (L2-L4), femoral neck and left total hip regions using DXA. All DXA scans were performed with the same bone densitometer (Lunar Encore; GE Medical Systems, Madison, Wisconsin, USA) by the same trained technicians. The BMD results were compared with average BMD values from age-matched and sex-matched controls, available in a large population database (Hologic) and expressed as a SD of the mean to prevent bias due to age and sex.

\section{FRAX score assessment}

The FRAX score, as a 10-year FRAX, is composed of 11 clinical factors, including age (years), sex, weight $(\mathrm{kg})$, height $(\mathrm{cm})$, glucocorticoid use (defined as a dose of $7.5 \mathrm{mg}$ of prednisolone or the equivalent within 3 months), rheumatoid arthritis, secondary osteoporosis, excessive alcohol intake ( $>3$ units/day), current smoker, personal fracture history, parental hip fracture history and optional DXA measured BMD at the femoral neck. The score can be calculated online ${ }^{24}$ using risk stratification according to the Taiwan clinical practice guideline recommendations. ${ }^{25}$ This allows patient stratification into low-risk (major bone fracture $<10 \%$, hip fracture $<1.5 \%$ ), medium-risk (major bone fracture 10\%-20\%, hip fracture $1.5 \%-3 \%$ ) or high-risk (major bone fracture $>20 \%$, hip fracture $>3 \%$ ) groups for the development of a major osteoporotic fracture (including clinical vertebral, humerus or forearm) or hip fracture over a 10-year period.

\section{Definitions of osteopenia and osteoporosis}

The definitions of osteopenia and osteoporosis were based on T-scores, according to the WHO criteria. ${ }^{20} \mathrm{~A}$ BMD measurement of 1-2.5 SDs below the mean for young adults $(-2.5<$ Tscore $\leq-1)$ was defined as osteopenia, whereas a T-score $\leq 2.5$ SDs below the mean was defined as osteoporosis. ${ }^{21}$ The risk of fractures increases 1.5-3 times, or more, for each SD decrease in BMD.

\section{Statistical analysis}

We tested the normality of continuous variables by using the Kolmogorov-Smirnov test. Most of the null hypothesis was rejected, except for waist-to-hip ratio, waist-to-height ratio, systolic BP and total cholesterol. Therefore, data of 
all continuous variables were presented as median and IQR. We tested the trends of clinical characteristics across BMD (normal, osteopenia and osteoporosis) groups by using the Jonckheere-Terpstra non-parametric test for continuous variables or the Cochran-Armitage $\chi^{2}$ test for categorical variables (ie, prevalence of HCV). The clinical characteristics of $\mathrm{HCV}$-seropositive and $\mathrm{HCV}$-seronegative participants were compared by using the Mann-Whitney $\mathrm{U}$ test for continuous variables or $\chi^{2}$ tests for categorical variables. The independent association of osteoporosis and osteopenia with HCV infection was tested by using logistic regression analyses in which covariates were adjusted in the multivariable models, and HCV seropositivity was treated as the independent variable. In addition,

Table 1 Characteristic of the study participants by bone mineral density status

\begin{tabular}{|c|c|c|c|c|c|}
\hline Variable & $\begin{array}{l}\text { Total } \\
(n=636)\end{array}$ & $\begin{array}{l}\text { Normal } \\
(n=195)\end{array}$ & $\begin{array}{l}\text { Osteopenia } \\
(n=305)\end{array}$ & $\begin{array}{l}\text { Osteoporosis } \\
(n=136)\end{array}$ & $\mathbf{P}$ trend \\
\hline Age, years & $65(13)$ & $60(11)$ & $66(12)$ & $71(12)$ & $<0.001^{*}$ \\
\hline Age & & & & & $<0.001^{*}$ \\
\hline 40-64 years & $303(47.6)$ & $139(71.3)$ & $129(42.3)$ & $35(25.7)$ & \\
\hline$\geq 65$ years & $333(52.4)$ & $56(28.7)$ & $176(57.7)$ & $101(74.3)$ & \\
\hline \multicolumn{6}{|l|}{ Substance use, n (\%) } \\
\hline Smoking & $15(2.4)$ & $5(2.6)$ & $8(2.6)$ & $2(1.5)$ & 0.557 \\
\hline Alcohol & $38(6.0)$ & $12(6.2)$ & $24(7.9)$ & $2(1.5)$ & 0.130 \\
\hline Betel nut & $7(1.1)$ & $1(0.5)$ & $3(1.0)$ & $3(2.2)$ & 0.160 \\
\hline \multicolumn{6}{|l|}{ Anthropometric measures } \\
\hline Body weight, kg & $60(13)$ & $64(13)$ & $61(12)$ & $56(11)$ & $<0.001^{*}$ \\
\hline Body mass index, $\mathrm{kg} / \mathrm{m}^{2}$ & $26(5)$ & $27(5)$ & $26(5)$ & $24(5)$ & $<0.001^{*}$ \\
\hline \multicolumn{3}{|c|}{ Lipschitz classification for $\geq 65$ years, $n(\%)$} & & & $<0.001^{*}$ \\
\hline$<22 \mathrm{~kg} / \mathrm{m}^{2}$ & $31(9.3)$ & $0(0.0)$ & $12(6.8)$ & 19 (18.8) & \\
\hline $22.0-27 \mathrm{~kg} / \mathrm{m}^{2}$ & $169(50.8)$ & $20(35.7)$ & $92(52.3)$ & $57(56.4)$ & \\
\hline$>27 \mathrm{~kg} / \mathrm{m}^{2}$ & $133(39.9)$ & $36(64.3)$ & $72(40.9)$ & $25(24.8)$ & \\
\hline Waist circumference, $\mathrm{cm}$ & $83(13)$ & $83(13)$ & $83(13)$ & $79(11)$ & $0.002^{*}$ \\
\hline Waist-to-hip ratio & $0.86(0.09)$ & $0.85(0.08)$ & $0.86(0.09)$ & $0.86(0.09)$ & 0.288 \\
\hline Waist-to-height ratio & $0.54(0.09)$ & $0.54(0.08)$ & $0.54(0.09)$ & $0.52(0.08)$ & 0.271 \\
\hline Systolic BP, mm Hg & $137(29)$ & $134(29)$ & $139(29)$ & $136(26)$ & 0.407 \\
\hline Diastolic BP, mm Hg & $77(15)$ & $75(15)$ & $78(17)$ & $76(14)$ & 0.933 \\
\hline \multicolumn{6}{|l|}{ Lab data } \\
\hline Creatinine, $\mathrm{mg} / \mathrm{dL}$ & $0.80(0.19)$ & $0.80(0.22)$ & $0.80(0.17)$ & $0.80(0.19)$ & 0.178 \\
\hline Uric acid, mg/dL & $5.4(1.7)$ & $5.5(1.8)$ & $5.4(1.5)$ & $5.1(1.9)$ & $0.043^{*}$ \\
\hline ALT, U/L & $22(9)$ & $22(10)$ & $22(8)$ & $23(10)$ & 0.110 \\
\hline AST, U/L & $22(14)$ & $23(16)$ & $22(13)$ & $21(14)$ & 0.059 \\
\hline $\mathrm{LDL}, \mathrm{mg} / \mathrm{dL}$ & $117(45)$ & $119(49)$ & $118(40)$ & $111(45)$ & 0.146 \\
\hline $\mathrm{TC}, \mathrm{mg} / \mathrm{dL}$ & $194(54)$ & $199(59)$ & $194(49)$ & $192(52)$ & 0.217 \\
\hline $\mathrm{TG}, \mathrm{mg} / \mathrm{dL}$ & $97(67)$ & $93(61)$ & $101(66)$ & $93(71)$ & 0.721 \\
\hline $\mathrm{HDL}, \mathrm{mg} / \mathrm{dL}$ & $54(17)$ & $53(16)$ & $55(17)$ & $52(18)$ & 0.588 \\
\hline Fasting sugar, mg/dL & $98(20)$ & $98(22)$ & $99(19)$ & $97(20)$ & 0.227 \\
\hline Albumin, mg/dL & $4.4(0.3)$ & $4.4(0.3)$ & $4.4(0.3)$ & $4.4(0.3)$ & $0.005^{\star}$ \\
\hline Albumin (mean $\pm S D)$ & $4.41 \pm 0.31$ & $4.44 \pm 0.30$ & $4.41 \pm 0.32$ & $4.36 \pm 0.31$ & - \\
\hline Total protein, g/dL & $7.4(0.6)$ & $7.4(0.6)$ & $7.3(0.5)$ & $7.3(0.8)$ & 0.613 \\
\hline HBV, n (\%) & $93(14.6)$ & $30(15.4)$ & $45(14.8)$ & $18(13.2)$ & 0.597 \\
\hline HCV, n (\%) & 205 (32.2) & 46 (23.6) & $103(33.8)$ & $56(41.2)$ & $0.001^{*}$ \\
\hline
\end{tabular}

Continuous data were presented as median and IQR.

${ }^{*} \mathrm{P}<0.05$;

ALT, alanine aminotransferase; AST, aspartate aminotransferase; BP, blood pressure; HBV, hepatitis B virus; HCV, hepatitis C virus; HDL, highdensity lipoprotein; LDL, low-density lipoprotein; TC, total cholesterol; TG, triglyceride. 
the 10-year fracture risk between the HCV-seropositive and HCV-seronegative groups was measured using two sample t-tests. All analyses were performed by using SPSS V.22.

\section{Patient and public involvement}

The study was designed to examine the hypothesis that HCV seropositivity is independently associated with menopausal BMD loss. However, patients were not included in the design of the survey instrument, recruitment or conduct of the study. Patients who participated did so anonymously; therefore, the study team will be unable to disseminate the results to study participants.

\section{RESULTS}

\section{Characteristics across BMD groups}

Table 1 shows the characteristics of the 636 menopausal women. The study participants had a median age of 65 years and a low proportion of substance use. The prevalence of HBV and HCV were $14.6 \%$ and $32.2 \%$, respectively. We further classified the participants into three groups according to their T-scores: normal, osteopenia and osteoporosis. The prevalence of menopausal osteoporosis was $21.4 \%(136 / 636)$. A strong association was observed between older age and lower levels of BMD ( $\mathrm{p}$ trend $<0.001$ ). Lower T-scores are correlated to lower values of body weight, BMI, waist circumference and mean albumin level (all, $p$ trend $<0.01$ ). The study group significantly differed in the Lipschitz classification for participants $\geq 65$ years $(\mathrm{p}<0.001)$. The proportion of underweight $\left(<22 \mathrm{~kg} / \mathrm{m}^{2}\right)$ was highest in the osteoporosis group, followed by the osteopenia and normal group ( $18.8 \%$ vs $6.8 \%$ vs $0 \%)$. Of note, the prevalence of HCV seropositivity was the highest in the osteoporosis group, followed by the osteopenia group, and was lowest in the normal group ( $41.2 \%$ vs $33.8 \%$ vs $23.6 \%$, respectively; $p$ trend $<0.001)$ (table 1).

\section{HCV seropositivity characteristics}

HCV-seropositive patients were older than HCV-seronegative subjects (68 vs 64 years, $\mathrm{p}<0.001$ ). There were no significant differences between the HCV groups with respect to the proportion of substances used and their anthropometric indices. Poor abnormal liver function, lower mean albumin/total protein level and a higher proportion of metabolic components, such as high BP, high fasting glucose levels and disturbed lipid profiles, were observed in the HCV-seropositive group than in the seronegative group $(\mathrm{p}<0.05)$.

The two groups did not significantly differed in the Lipschitz classification for participants $\geq 65$ years $(p=0.061)$. Notably, T-scores in various anatomic locations (lumbar, hip and femoral neck) are significantly lower in the HCV-seropositive group than in the HCV-seronegative group (table 2).

\section{Association of FRAX score with HCV seropositivity}

Figure 1 shows that the prevalence of HCV seropositivity increases significantly according to the FRAX
Table 2 Characteristic of the study participants by the presence of HCV $(n=636)$

\begin{tabular}{|c|c|c|c|}
\hline Variable & $\begin{array}{l}\text { HCV } \\
\text { seropositive } \\
(n=205)\end{array}$ & $\begin{array}{l}\text { HCV } \\
\text { seronegative } \\
(n=431)\end{array}$ & $P$ value \\
\hline Age, years & $68(13)$ & $64(12)$ & $<0.001^{*}$ \\
\hline Age & & & $<0.001^{*}$ \\
\hline 40-64 years & $74(36.1)$ & $229(53.1)$ & \\
\hline$\geq 65$ years & $131(63.9)$ & $202(46.9)$ & \\
\hline \multicolumn{4}{|l|}{ Substance use, n (\%) } \\
\hline Smoking & $7(3.4)$ & $8(1.9)$ & 0.226 \\
\hline Alcohol & $10(4.9)$ & $28(6.5)$ & 0.421 \\
\hline Betel nut & $4(2.0)$ & $3(0.7)$ & 0.156 \\
\hline \multicolumn{4}{|l|}{ Anthropometric measures } \\
\hline Body weight, kg & $59(14)$ & $61(12)$ & 0.135 \\
\hline $\begin{array}{l}\text { Body mass index, } \\
\mathrm{kg} / \mathrm{m}^{2}\end{array}$ & $25(5)$ & $26(5)$ & 0.677 \\
\hline \multicolumn{3}{|c|}{ Lipschitz classification for $\geq 65$ years, n (\%) } & 0.061 \\
\hline$<22 \mathrm{~kg} / \mathrm{m}^{2}$ & $17(13.0)$ & $14(6.9)$ & \\
\hline $22.0-27 \mathrm{~kg} / \mathrm{m}^{2}$ & $70(53.4)$ & $99(49.0)$ & \\
\hline$>27 \mathrm{~kg} / \mathrm{m}^{2}$ & $44(33.6)$ & $89(44.1)$ & \\
\hline $\begin{array}{l}\text { Waist circumference, } \\
\mathrm{cm}\end{array}$ & $82(12)$ & $83(12)$ & 0.632 \\
\hline Waist-to-hip ratio & $0.87(0.08)$ & $0.85(0.09)$ & $0.028^{*}$ \\
\hline Waist-to-height ratio & $0.54(0.09)$ & $0.53(0.09)$ & 0.204 \\
\hline Systolic BP, mm Hg & $142(27)$ & $134(29)$ & $0.002^{*}$ \\
\hline Diastolic BP, mm Hg & $78(16)$ & $76(15)$ & $0.017^{\star}$ \\
\hline \multicolumn{4}{|l|}{ Lab data } \\
\hline Creatinine, $\mathrm{mg} / \mathrm{dL}$ & $0.80(0.19)$ & $0.80(0.19)$ & 0.826 \\
\hline Uric acid, mg/dL & $5.5(1.7)$ & $5.3(1.6)$ & 0.473 \\
\hline ALT, U/L & $26(17)$ & $21(7)$ & $<0.001^{*}$ \\
\hline AST, U/L & $26(24)$ & $20(11)$ & $<0.001^{*}$ \\
\hline LDL, mg/dL & $109(42)$ & $121(43)$ & $<0.001^{*}$ \\
\hline $\mathrm{TC}, \mathrm{mg} / \mathrm{dL}$ & $183(51)$ & $198(53)$ & $<0.001^{*}$ \\
\hline $\mathrm{TG}, \mathrm{mg} / \mathrm{dL}$ & $97(62)$ & $96(68)$ & 0.226 \\
\hline HDL, mg/dL & $51(16)$ & $55(17)$ & $0.005^{*}$ \\
\hline Fasting sugar, mg/dL & $102(26)$ & $97(18)$ & $0.010^{*}$ \\
\hline Albumin, mg/dL & $4.4(0.3)$ & $4.4(0.3)$ & $<0.001^{*}$ \\
\hline Albumin (mean $\pm S D$ ) & $4.33 \pm 0.32$ & $4.45 \pm 0.30$ & - \\
\hline Total protein, $\mathrm{g} / \mathrm{dL}$ & $7.4(0.7)$ & $7.3(0.5)$ & $0.018^{*}$ \\
\hline HBV, n (\%) & $30(14.6)$ & $63(14.6)$ & 0.995 \\
\hline \multicolumn{4}{|l|}{ DXA report $\left(\mathrm{g} / \mathrm{cm}^{2}\right)$} \\
\hline Lumbar spine & $1.01(0.22)$ & $1.08(0.28)$ & $0.027^{*}$ \\
\hline Total hip & $0.78(0.17)$ & $0.81(0.18)$ & 0.063 \\
\hline Femoral neck & $0.87(0.20)$ & $0.88(0.19)$ & $0.031^{*}$ \\
\hline
\end{tabular}

Continuous data were presented as median and IQR. ${ }^{*} \mathrm{P}<0.05$.

ALT, alanine aminotransferase; AST, aspartate aminotransferase; BP, blood pressure; DXA, dual-energy X-ray absorptiometry; HBV, hepatitis B virus; HCV, hepatitis $\mathrm{C}$ virus; HDL, high-density lipoprotein; LDL, low-density lipoprotein; TC, total cholesterol; TG, triglyceride. 


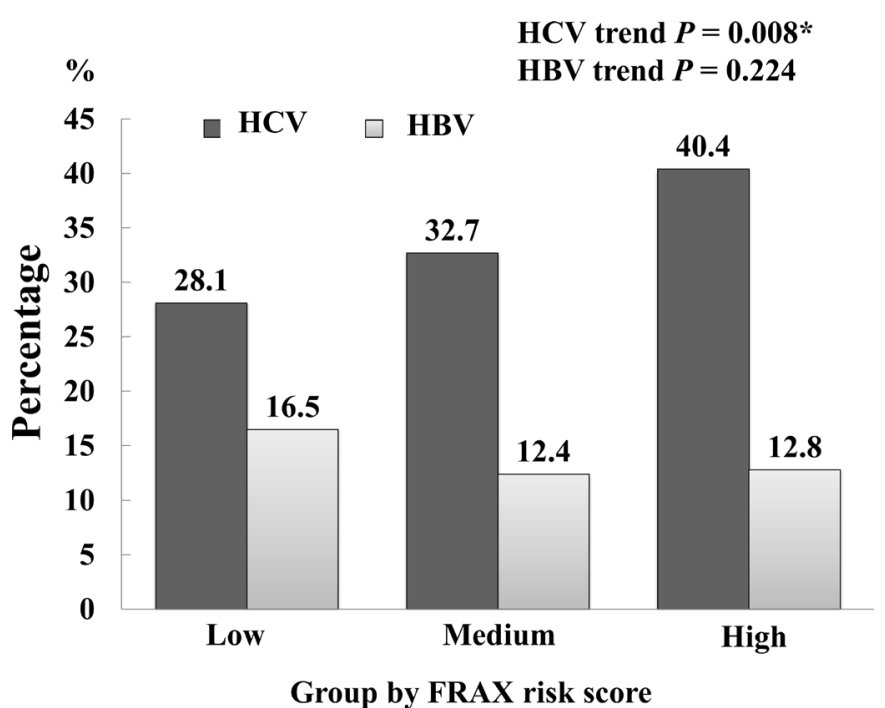

Figure 1 The prevalence of HCV and HBV seropositivity among different FRAX assessed risk groups: low-risk (major bone fracture $<10 \%$, hip fracture $<1.5 \%$ ), medium-risk (major bone fracture 10\%-20\%, hip fracture 1.5\%-3\%) or high-risk (major bone fracture $>20 \%$, hip fracture $>3 \%$ ) groups for the development of fractures over a 10-year period. FRAX, fracture risk assessment tool; HBV, hepatitis B virus; HCV, hepatitis $\mathrm{C}$ virus.

score-defined risk classification (low vs medium vs high risk: $28.1 \%$ vs $32.7 \%$ vs $40.4 \%$; p trend=0.008). In contrast, a similar trend with HBV seropositivity was not observed ( $p$ trend=0.224). According to the FRAX score assessments, HCV-seropositive patients have significantly higher 10-year probabilities of major osteoporotic fractures $(11.3 \% \pm 7.6 \%$ vs $9.0 \pm 6.8 \% ; \mathrm{p}<0.001)$ and hip fractures $(3.4 \% \pm 4.7 \%$ vs $2.3 \pm 4.9 \% ; \mathrm{p}=0.006)$ than the HCV-seronegative participants (figure 2).

\section{Independent association between HCV and osteoporosis}

Table 3 shows the association between HCV seropositivity and osteoporosis/osteopenia using various adjustment models according to substance use, anthropometric

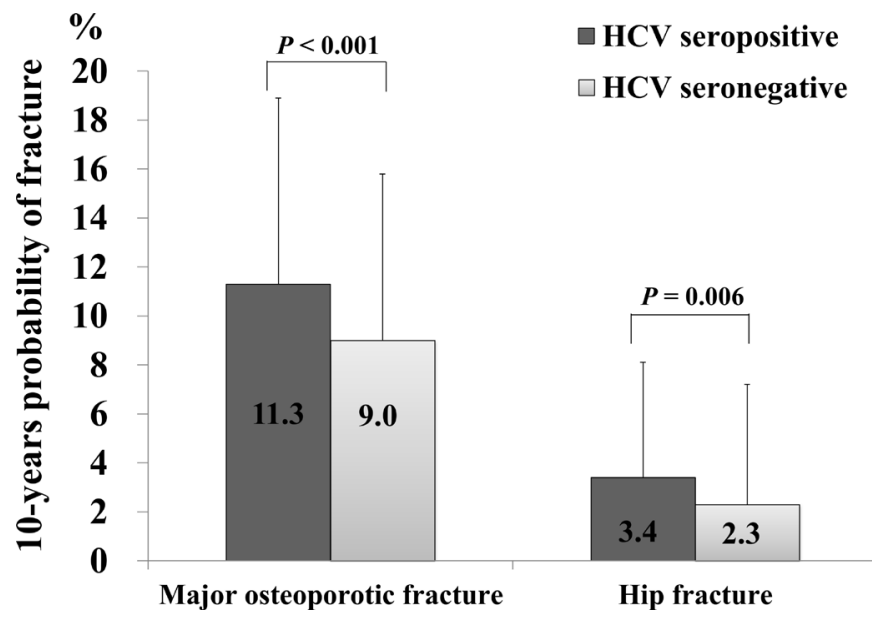

Figure 2 The 10-year probability of major osteoporotic fractures and hip fractures among HCV-seropositive and $\mathrm{HCV}$-seronegative participants. HCV, hepatitis $\mathrm{C}$ virus. measures, inflammatory index, lipid profiles, HBV and age sequentially. The results demonstrate that HCV is an independent risk factor for osteoporosis in models 1-6. After adjusting for age in model 7 , the trend tends to a higher osteoporosis risk in the HCV-positive group remains $(p=0.068)$. For the composite outcome (osteopenia and osteoporosis), HCV is an independent factor in each model, even after adjusting for age and other covariates (adjusted OR: 1.80; 95\% CI 1.16 to 2.81; $\mathrm{p}=0.009$ ), indicating that HCV may be a useful index for identifying BMD loss.

\section{DISCUSSION}

This study showed that a significant association exists between HCV seropositivity and lower BMD values in postmenopausal women. HCV-seropositive patients had an $80 \%$ increased relative risk for composite of osteopenia and osteoporosis, compared with HCV-seronegative subjects (adjusted OR: 1.8; $\mathrm{p}=0.009$ ). Apart from age, $\mathrm{HCV}$ also contributed to be an osteoporotic fracture risk, based on the FRAX prediction score.

\section{Factors associated with lower BMDs in women}

For subjects with osteoporosis and a mean age $>70$ years in our study, age was an independent risk factor for osteoporosis development, in addition to several known confounding factors. ${ }^{3}$ Furthermore, the osteoporosis prevalence in our postmenopausal population was $21.4 \%$, which was higher than that reported in a meta-analysis study in China (14.2\%). ${ }^{26}$ Despite the influence of age and oestrogen deficiency on BMD, multiple confounders, such as milk or calcium insufficiency, ${ }^{3}$ physical inactivity, smoking and alcohol consumption, ${ }^{5}$ may accelerate postmenopausal osteoporosis. Reduced smoking and alcohol consumption in our study population ameliorated the influence of substance use on BMD loss. ${ }^{35} \mathrm{HCV}$ seropositive subjects with a relatively lower body weight and BMI might have dyspepsia, nutrition deficiency, ${ }^{27}$ gastric disorders or hepatic cachexia in chronic infection. Although, BMI, as the traditional tool to assess malnutrition and obesity, is not appropriate to accurately differentiate between important body weight components. ${ }^{23}$ Barbu et $a t^{28}$ found that chronic hepatitis $\mathrm{C}$ patients with lower BMIs and body fat compositions tended to have significant BMD loss, in agreement with our findings.

\section{Impact of HCV on menopausal osteopenia and osteoporosis} In $\mathrm{HCV} / \mathrm{HBV}$ hyperendemic regions, ${ }^{13}$ women might experience a spectrum of lesions, from osteopenia to osteoporotic fractures, due to chronic liver disease ${ }^{45910}$ during the early menopausal stage. Advanced liver fibrosis, with cirrhosis, is the key contributor of osteoporosis in chronic HCV infections. ${ }^{9}{ }^{10}$ Nutrition deficiency is predominant in patients with advanced cirrhosis, ${ }^{27}$ which also contributes to the hypoalbuminaemia and vitamin D deficiency in patients with chronic HCV infections. ${ }^{29}$ In another respect, vitamin D supplements might prevent 
Table 3 Association of HCV with risk of osteopenia and osteoporosis in various adjustment models

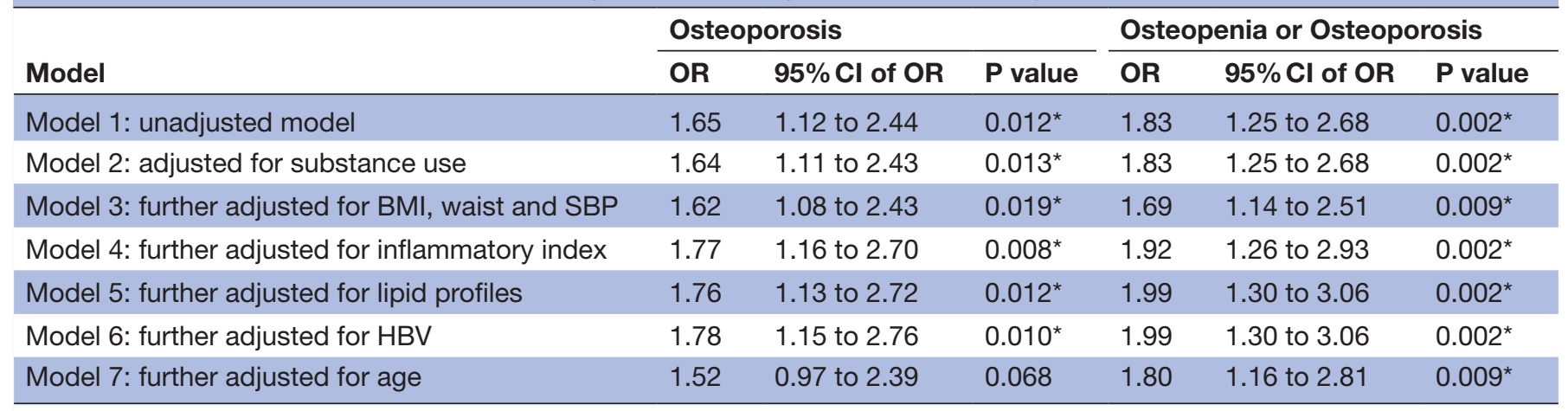

${ }^{*} \mathrm{P}<0.05$.

BMI, body mass index; HBV, hepatitis B virus; HCV, hepatitis C virus; SBP, systolic blood pressure.

advanced cirrhotic changes in chronic liver disease and potential hypoalbuminaemia. ${ }^{7}$ Both albumin and vitamin D deficiencies disturb calcium metabolism and parathyroid hormone homeostasis. ${ }^{29} 30$ Despite the exclusion of patients with cirrhosis in our study and some of the HCV seropositive subjects who might have lesser degrees of fibrosis or cirrhosis, our findings demonstrated that chronic HCV infection tends to be another independent risk factor of BMD loss in non-cirrhotic population, even in addition to age and HBV infection.

Agostino $e t a l^{\beta 1}$ showed the reduced bone mineral quality and stiffness by using quantitative CT in menopausal women with HCV infections; however, they suggested an underestimation of DXA measurements would result in a lower prevalence of BMD loss in patients with chronic liver disease. Their observations indicated that the incidence of osteoporosis might be underestimated in our study; regardless, the fracture risk should not be ignored because of the higher fracture rate associated with mildly reduced DXA results in the Diamond study. ${ }^{17}$ Like the FRAX investigation in a cirrhosis population, ${ }^{18}$ our study showed that a higher FRAX score indicated a potential osteoporotic fracture risk in HCV-infected menopausal women, before they advanced to the cirrhotic stage.

\section{Inflammatory link between HCV and hepatic osteoporosis}

As many extrahepatic manifestations, including cryoglobulinaemia, vasculitis, hepatic steatosis, and systemic atherosclerosis, occur in patients with chronic hepatitis C, osteoporosis might also be thought of as a consequence of inflammation ${ }^{32}$ due to HCV-related autoimmunity. Our study demonstrated hepatic inflammation with relatively higher transaminase values in osteoporotic and HCV seropositive population. Sclerostin, secreted by osteocytes, imposes a paradoxical intensity on physical and disease conditions. ${ }^{33}$ In postmenopausal women, sclerostin is negatively correlated with bone turnover and osteoporosis. ${ }^{34}$ Although higher sclerostin levels are associated with alcoholic liver disease,${ }^{35}$ nutrition deficiency and lower BMI status, ${ }^{36}$ González-Reimers $e t a l^{37}$ found that sclerostin levels are also higher in chronic HCV-infected patients with lower BMD, in contrast to what is expected in the menopausal period. In this instance, the decreased BMD is related to extrahepatic immunological reactions and systemic inflammation, which are consistent with positive correlation between sclerostin and tumour necrosis factor- $\alpha .^{37}$

\section{Limitations}

This study had several limitations. First, this was a cross-sectional study with an informational bias because the demographic parameters concerning menopausal history, disease, fracture experience and drug history were self-reported by the subjects. We did not have any information available regarding calcium and 25-OH vitamin D supplement usage or levels; daily medication details were also unavailable. Second, the duration of HCV infection, hepatitis $\mathrm{C}$ virus load, antiviral therapy history and viral eradication status were not obtained in the check-up. We tried to exclude severe hepatic disease, such as cirrhosis and any other causes for hepatic surgery. Third, we did not know the patient histories of lumbar spinal osteoarthritis or injury, both of which might influence and disturb BMD values. Fourth, trabecular bone score would be used for accurate bone quality analysis and correlated with FRAXbase predicted fracture; however, we could not apply this with our current equipment. Fifth, interscanner variation and misclassification were minimal with high intrascanner reproducibility because all women were scanned using the same machine by the same technician.

\section{CONCLUSION}

Our study showed a strong association between HCV seropositivity and lower BMD in postmenopausal women. These results suggest that HCV infection might be a risk factor for osteopenia and potential osteoporotic fractures according to FRAX score. A future, larger cohort could provide more evidence of osteoporosis prevention in both sexes.

\section{Author affiliations}

${ }^{1}$ Department of Cardiology, Chang Gung Memorial Hospital, Chiayi, Taiwan

2Department of Internal Medicine, Chang Gung Memorial Hospital, Chiayi, Taiwan 
${ }^{3}$ Department of Orthopedic Surgery, Chang Gung Memorial Hospital, Yunlin, Taiwan ${ }^{4}$ Department of Infectious Diseases, Chang Gung Memorial Hospital, Chiayi, Taiwan ${ }^{5}$ Department of Pulmonary Disease and Critical Care, Chang Gung Memorial Hospital, Yunlin, Taiwan

${ }^{6}$ Department of Respiratory Care, Chang Gung University of Science and Technology, Chiayi, Taiwan

${ }^{7}$ Department of Hepato-Gastroenterology, Chang Gung Memorial Hospital, Yunlin, Taiwan

${ }^{8}$ Department of Nursing, Chang Gung University of Science and Technology, Chiayi, Taiwan

${ }^{9}$ Department of Nursing, Chang Gung University, Taoyuan, Taiwan

Acknowledgements We would like to thank those participants in this study and all staff in the Yunlin Chang Gung Memorial Hospital for support in making this study possible. We also thank Alfred Hsing-Fen Lin for the assistance with statistics.

Contributors All authors reviewed the manuscript and completed final approval. Study concept and design: M-SL, P-HC, P-CW, H-SL, T-JH and M-YC; acquisition of data: P-CW, H-SL and S-TC; analysis and interpretation of data: W-NC and Y-YM; manuscript draft: $\mathrm{M}-\mathrm{SL}$ and $\mathrm{M}-\mathrm{YC}$; critical revision of the manuscript for important intellectual content: P-HC, H-SL, T-JH and M-YC.

Funding The study was supported by a grant from the Taiwan Formosa Plastic Company (FCRPF690011) and Chang Gung Memorial Hospital (BMRP148) as well as (CMRPGMF0012).

Competing interests None declared.

Patient consent Obtained.

Ethics approval Ethical approval was provided by the institutional review board of the ethical committee of Chang Gung Memorial Hospital (IRB: 104-9925C).

Provenance and peer review Not commissioned; externally peer reviewed.

Data sharing statement № additional data are available.

Open access This is an open access article distributed in accordance with the Creative Commons Attribution Non Commercial (CC BY-NC 4.0) license, which permits others to distribute, remix, adapt, build upon this work non-commercially, and license their derivative works on different terms, provided the original work is properly cited, appropriate credit is given, any changes made indicated, and the use is non-commercial. See: http://creativecommons.org/licenses/by-nc/4.0/.

\section{REFERENCES}

1. Häussler B, Gothe H, Göl D, et al. Epidemiology, treatment and costs of osteoporosis in Germany--the BoneEVA Study. Osteoporos Int 2007;18:77-84

2. Pietschmann P, Rauner M, Sipos W, et al. Osteoporosis: an agerelated and gender-specific disease--a mini-review. Gerontology 2009;55:3-12.

3. Chen PH, Lin MS, Huang TJ, et al. Prevalence of and factors associated with adopting bone health promoting behaviours among people with osteoporosis in Taiwan: a cross-sectional study. BMJ Open 2017;7:e015980.

4. Carey EJ, Balan V, Kremers WK, et al. Osteopenia and osteoporosis in patients with end-stage liver disease caused by hepatitis $\mathrm{C}$ and alcoholic liver disease: not just a cholestatic problem. Liver Transpl 2003;9:1166-73

5. Paccou J, Edwards $\mathrm{MH}$, Ward K, et al. Relationships between bone geometry, volumetric bone mineral density and bone microarchitecture of the distal radius and tibia with alcohol consumption. Bone 2015;78:122-9.

6. Sambrook PN, Kotowicz M, Nash P, et al. Prevention and treatment of glucocorticoid-induced osteoporosis: a comparison of calcitriol, vitamin D plus calcium, and alendronate plus calcium. J Bone Miner Res 2003;18:919-24.

7. Cholongitas E, Theocharidou E, Goulis J, et al. Review article: the extra-skeletal effects of vitamin D in chronic hepatitis $C$ infection. Aliment Pharmacol Ther 2012;35:634-46.

8. Guañabens N, Parés A, Ros I, et al. Severity of cholestasis and advanced histological stage but not menopausal status are the major risk factors for osteoporosis in primary biliary cirrhosis. J Hepatol 2005;42:573-7.

9. Lupoli R, Di Minno A, Spadarella G, et al. The risk of osteoporosis in patients with liver cirrhosis: a meta-analysis of literature studies. Clin Endocrinol 2016;84:30-8.
10. Wariaghli G, Mounach A, Achemlal L, et al. Osteoporosis in chronic liver disease: a case-control study. Rheumatol Int 2010;30:893-9.

11. Collier JD, Ninkovic M, Compston JE. Guidelines on the management of osteoporosis associated with chronic liver disease. Gut 2002;50(Suppl 1):1i-9.

12. World Health Organization. Global health sector strategy on viral hepatitis 2016-2021: towards ending viral hepatitis. $2016 \mathrm{http} / / / a p p s$. who.int/iris/bitstream/10665/246177/1/WHO-HIV-2016.06-eng.pdf (Accessed Feb 2018).

13. $\mathrm{Hu} \mathrm{JH}$, Chen MY, Yeh CT, et al. Sexual dimorphic metabolic alterations in hepatitis $C$ virus-infected patients: a community-based study in a hepatitis $\mathrm{B} /$ hepatitis $\mathrm{C}$ Virus hyperendemic area. Medicine 2016;95:e3546.

14. Schiefke I, Fach A, Wiedmann M, et al. Reduced bone mineral density and altered bone turnover markers in patients with noncirrhotic chronic hepatitis B or C infection. World J Gastroenterol 2005;11:1843-7.

15. Cacoub P, Gragnani L, Comarmond C, et al. Extrahepatic manifestations of chronic hepatitis C virus infection. Dig Liver Dis 2014;46:S165-73.

16. Wijarnpreecha $\mathrm{K}$, Thongprayoon $\mathrm{C}$, Panjawatanan $\mathrm{P}$, et al. Hepatitis $C$ virus infection and risk of osteoporosis: a meta-analysis. Saudi J Gastroenterol 2017;23:S1088-221.

17. Hansen AB, Omland LH, Krarup H, et al. Fracture risk in hepatitis $C$ virus infected persons: results from the DANVIR cohort study. $J$ Hepatol 2014;61:15-21.

18. A El-Atrebi K, T El-Bassyouni H, A El-Atrebi A, et al. Department of General Medicine and Hepatology, National Hepatology and Tropica Medicine Research Institute, Cairo, Egypt. Osteoporosis in Chronic Hepatitis C Virus with Advanced Liver Fibrosis. J Gastroenterol Hepatol Res 2014;3:1392-5.

19. Bedimo R, Maalouf NM, Lo Re V. Hepatitis C virus coinfection as a risk factor for osteoporosis and fracture. Curr Opin HIV AIDS 2016;11:285-93.

20. Czerwiński E, Badurski JE, Marcinowska-Suchowierska E, et al. Current understanding of osteoporosis according to the position of the World Health Organization (WHO) and International Osteoporosis Foundation. Ortop Traumatol Rehabil 2007;9:337-56.

21. Dagan N, Cohen-Stavi C, Leventer-Roberts M, et al. External validation and comparison of three prediction tools for risk of osteoporotic fractures using data from population based electronic health records: retrospective cohort study. BMJ 2017;356:i6755.

22. Nicoll R, Black A, Bailey L, et al. Fracture risk calculation tool enhances dual-energy X-ray absorptiometry scan referral pathway in cirrhosis patients. Eur J Gastroenterol Hepatol 2016;28:757-61.

23. Gonzalez MC, Correia M, Heymsfield SB, et al. A requiem for $\mathrm{BMI}$ in the clinical setting. Curr Opin Clin Nutr Metab Care 2017;20:314-21.

24. FRAX-WHO Facture Risk Assessment Tool. https://www.sheffield.ac uk/FRAX/tool.aspx?country=26.

25. Hwang JS, Chan DC, Chen JF, et al. Clinical practice guidelines for the prevention and treatment of osteoporosis in Taiwan: summary. $J$ Bone Miner Metab 2014;32:10-16.

26. Han YJ, Tie XJ, Tuoheti Y. Meta-analysis on the prevalence rate of osteoporosis in the middle-aged and elderly in China. Chin J Tissue Eng Res 2014;18:1129-34.

27. Johnson TM, Overgard EB, Cohen AE, et al. Nutrition assessment and management in advanced liver disease. Nutr Clin Pract 2013;28:15-29.

28. Barbu EC, Chițu-Tișu CE, Lazăr M, et al. Body composition changes in patients with chronic hepatitis C. J Gastrointestin Liver Dis 2016;25:323-9.

29. Villar LM, Del Campo JA, Ranchal I, et al. Association between vitamin D and hepatitis $\mathrm{C}$ virus infection: a meta-analysis. World $\mathrm{J}$ Gastroenterol 2013;19:5917-24.

30. Agarwal A, Gupta SK, Sukumar R. Hyperparathyroidism and malnutrition with severe vitamin D deficiency. World J Surg 2009;33:2303-13.

31. Gaudio A, Pennisi P, Muratore F, et al. Reduction of volumetric bone mineral density in postmenopausal women with hepatitis $C$ viruscorrelated chronic liver disease: a peripheral quantitative computed tomography (pQCT) study. Eur J Intern Med 2012;23:656-60.

32. Lai JC, Shoback DM, Zipperstein J, et al. Bone mineral density, bone turnover, and systemic inflammation in non-cirrhotics with chronic hepatitis C. Dig Dis Sci 2015;60:1813-9.

33. Amrein K, Amrein S, Drexler C, et al. Sclerostin and its association with physical activity, age, gender, body composition, and bone mineral content in healthy adults. J Clin Endocrinol Metab 2012:97:148-54

34. Sheng Z, Tong D, Ou Y, et al. Serum sclerostin levels were positively correlated with fat mass and bone mineral density in central south Chinese postmenopausal women. Clin Endocrinol 2012;76:797-801. 
35. González-Reimers E, Martín-González C, de la Vega-Prieto MJ et al. Serum sclerostin in alcoholics: a pilot study. Alcohol Alcohol 2013;48:278-82.

36. Maïmoun L, Guillaume S, Lefebvre P, et al. Role of sclerostin and dickkopf-1 in the dramatic alteration in bone mass acquisition in adolescents and young women with recent anorexia nervosa. J Clin Endocrinol Metab 2014;99:E582-90.

37. González-Reimers E, López-Prieto J, Pelazas-González R, et al. Serum sclerostin in hepatitis $\mathrm{C}$ virus infected patients. J Bone Metab 2014;21:69-75. 